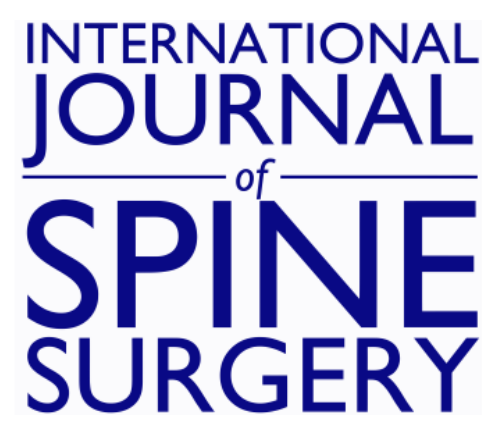

\title{
Charlson Comorbidity Index: An Inaccurate Predictor of Minimally Invasive Lumbar Spinal Fusion Outcomes
}

Nathaniel W. Jenkins, James M. Parrish, Michael T. Nolte, Caroline N. Jadczak, Cara E. Geoghegan, Shruthi Mohan, Nadia M. Hrynewycz and Kern Singh

Int J Spine Surg 2021, 15 (4) 770-779

doi: https://doi.org/10.14444/8099

http://ijssurgery.com/content/15/4/770

This information is current as of April 26, 2023.

Email Alerts Receive free email-alerts when new articles cite this article. Sign up at: http://ijssurgery.com/alerts 


\title{
Charlson Comorbidity Index: An Inaccurate Predictor of Minimally Invasive Lumbar Spinal Fusion Outcomes
}

\author{
NATHANIEL W. JENKINS, MS, JAMES M. PARRISH, MPH, MICHAEL T. NOLTE, MD, CAROLINE N. \\ JADCZAK, BS, CARA E. GEOGHEGAN, BS, SHRUTHI MOHAN, BS, NADIA M. HRYNEWYCZ, BS, KERN \\ SINGH, MD \\ Department of Orthopaedic Surgery, Rush University Medical Center, Chicago, Illinois
}

\begin{abstract}
Background: There is a scarcity of research on the Charlson Comorbidity Index (CCI) and its influence on minimum clinically important difference (MCID) achievement after minimally invasive (MIS) transforaminal lumbar interbody fusion (TLIF). The objective of this study is to detail the association between the CCI and attaining MCID after MIS TLIF.

Methods: A prospective surgical registry was retrospectively reviewed for spine surgeries between May 2015 and February 2019. Inclusion criteria were primary or revision, 1- or 2-level MIS TLIF procedures. Patients were stratified based on CCI score: 0 points (no comorbidities), 1-2 points (mild CCI), $\geq 3$ points (moderate CCI). Preoperative, intraoperative, and postoperative variables were assessed by subgroup using appropriate statistical analysis. Subgroups were analyzed with linear regression or $\chi^{2}$ tests for continuous or categorical variables, respectively. Subgroup scores, improvement, and MCID achievement were assessed at postoperative timepoints (eg, 6 weeks, 12 weeks, 6 months, and 1 year) for back and leg pain, Oswestry Disability Index (ODI), SF-12 Physical Composite Score (PCS), and PatientReported Outcomes Measurement Information System Physical Function (PROMIS PF).

Results: A total of 171 patients were included ( $n=51$ [no comorbidities], $n=73$ [mild CCI], and $n=47$ [moderate CCI]). Higher CCI patients were older and more likely to be smokers, diabetic, arthritic, hypertensive, or have a malignancy history $(P<0.003)$. Preoperatively, ODI and PROMIS PF were the only patient-reported outcomes with a significant association by CCI group $(P=0.015$ and 0.014$)$. Back pain was the only measure that had a significant association with the CCI subgroup at 1 year for score $(P=0.002)$ or MCID $(P=0.028)$.

Conclusions: By 1 year, regardless of the number of comorbidities, a similar proportion of patients undergoing MIS TLIF were able to achieve MCID for visual analog scale leg, SF-12 PCS, and PROMIS PF. Patients with higher comorbidities are not likely to experience a significant difference in symptom improvement. Regardless of CCI score, MIS TLIF can have a significant benefit for patients.

Level of Evidence: 4.

Clinical Relevance: Text.
\end{abstract}

Lumbar Spine

Keywords: minimally invasive transforaminal interbody fusion, spine surgery, minimal clinically important difference, Patient-Reported Outcomes Measurement Information System, PROMIS

\section{INTRODUCTION}

Minimally invasive (MIS) transforaminal lumbar interbody fusion (TLIF) has been shown to produce reliable radiographic and clinical outcomes, with potential for smaller wounds, less tissue disruption, and faster recovery times relative to the open procedure. ${ }^{1,2}$ As the technique continues to grow in popularity, the demographic range of patients undergoing the surgery is expanding. ${ }^{3}$ In addition, the number of elderly patients in the general population is increasing, and therefore, more patients who are indicated for surgery carry medical comorbidities. For example, an estimated $80 \%$ of the population age 65 and older have 1 or more comorbidities in addition to their index disease. ${ }^{4}$ As the number of MIS TLIFs performed increases, an understanding of outcomes for this broad patient population is paramount.

Although many researchers have focused on the association between medical comorbidities and the risk of perioperative complications, the relationship between comorbidities and patient-reported outcomes is also critical to grasp. ${ }^{5,6}$ Several studies have suggested that the presence of comorbidities may be associated with a smaller degree of improvement in 
patient-reported outcome measures (PROMs) after lumbar laminectomy and open lumbar fusion. ${ }^{7-9}$ However, the relationship between comorbid conditions and patient reported outcomes after the MIS TLIF technique remains unclear. ${ }^{10}$ Thus, the aim of the present study was to elucidate the association between comorbidity burden and achievement of the minimal clinically important difference (MCID) for several PROMs after MIS TLIF.

\section{METHODS}

\section{Patient Population}

After obtaining institutional review board approval (ORA\# 14051301), a prospectively maintained surgical registry was retrospectively reviewed for eligible patients undergoing TLIFs between May 2015 and February 2019. Inclusion criteria were 1or 2-level primary or revision MIS TLIFs. Our exclusion criteria removed patients if they did not complete a preoperative Patient-Reported Outcomes Measurement Information System (PROMIS) survey.

\section{Data Collection}

Baseline demographic variables were collected. These included age, gender, smoking status, body mass index (BMI), preoperative Charlson Comorbidity Index (CCI), and the presence of preoperative diagnoses including myocardial infarction, diabetes, arthritis, hypertension, neurological disease, peripheral vascular disease, as well as malignancy. Perioperative variables that were collected included number of operative fusion levels, operative time in minutes (from skin incision to closure), estimated blood loss (EBL) in millimeters, duration of postoperative inpatient stay in days and postoperative day (POD) of discharge. Complications, both intraoperative and postoperative, were recorded including urinary retention, atelectasis, nausea and vomiting, postoperative anemia, orthostatic hypotension, hyponatremia, altered mental status, or deep vein thrombosis. Preoperative and postoperative (eg, 6 weeks, 12 weeks, 6 months, and 1 year) patient-reported outcome measures (PROMs) were recorded, including visual analog scale (VAS) back, VAS leg, 12-item Short Form (SF-12) Physical Composite Score (PCS), PROMIS Physical Function (PROMIS PF), and Oswestry Disability Index (ODI). We attempted to improve patient follow-up rates in several ways. First, patients were encour- aged to follow up for each instrument assessment by receiving an email reminder at the beginning of any survey response window. Patients were allowed to complete their surveys at any point during a 4-week window around the evaluation timepoint. Additionally, each patient received at least 1 phone call reminding them to complete their questionnaires if they went longer than 2 weeks without completing. Finally, surveys did not require in-person visits and could be completed by mobile device or personal computer.

\section{Statistical Analysis}

Patients were stratified based on CCI score: 0 points (no comorbidities), 1 to 2 points (mild CCI), $\geq 3$ points (moderate $\mathrm{CCI}$ ). A $\chi^{2}$ test analyzed the association of $\mathrm{CCI}$ subgroups in the following variables: gender, smoking status, comorbid diagnoses, number of fusion levels, discharge day, and complications. Linear regression was used to measure the association of continuous variables (eg, age, operative time, EBL, length of stay, PROM score, and MCID achievement) with CCI. We evaluated if there was a difference in follow up among the $3 \mathrm{CCI}$ subgroups for patient follow-up proportions at each timepoint for all instrument scores. Achievement rate of MCID was compared between CCI groups using $\chi^{2}$ analysis. MCID values used were VAS back $=1.2,{ }^{11}$ VAS leg $=1.6,{ }^{11}$ ODI $=12.8,{ }^{11} \mathrm{SF}-12 \mathrm{PCS}=$ $4.0,{ }^{12}$ PROMIS PF $=8.0 .^{13}$ Statistical significance was set at $P<0.05$.

\section{Surgical Technique}

Indications for MIS TLIF included degenerative disc disease, recurrent disc herniations, spinal stenosis, and spondylolisthesis (degenerative or isthmic). All patients were intubated, induced into general anesthesia, and placed into the prone position. The surgeon made a $3-\mathrm{cm}$ incision on the pathological side, just lateral to the pedicle. A needle was advanced to the facet complex and the transverse process intersection. Guidewires were placed, and sequential dilators were used to confirm instrumentation positioning. Laminectomy was performed with a high-speed burr and a suction trap to recover bone fragments for use later with the interbody cage. A wide decompression was completed by resecting the pars in line with the inferior limit of the superior endplate. A facetectomy was accomplished by removing the articular processes, and the ligamentum flavum was resected. Visuali- 
Table 1. Baseline characteristics by Charlson Comorbidity Index (CCl) group. Boldface indicates statistical significance.

\begin{tabular}{|c|c|c|c|c|}
\hline Characteristic & $\mathrm{CCI}=\mathbf{0}(\mathrm{N}=\mathbf{5 1})$ & $\mathrm{CCI}=1-2(\mathrm{~N}=73)$ & $\mathrm{CCI} \geq 3(\mathrm{~N}=47)$ & $P$ Value $^{a}$ \\
\hline Age, mean $\pm \mathrm{SD}, \mathrm{y}$ & $40.9 \pm 7.5$ & $51.7 \pm 8.9$ & $60.4 \pm 7.4$ & $<\mathbf{0 . 0 0 1}$ \\
\hline \multicolumn{4}{|l|}{ Sex, \% (No.) } & \multirow[t]{3}{*}{0.050} \\
\hline Female & $27.5(14)$ & $35.6(26)$ & $51.1(24)$ & \\
\hline Male & $72.5(37)$ & $64.4(47)$ & 48.9. (23) & \\
\hline \multicolumn{4}{|l|}{ Smoking status, \% (No.) } & \multirow{3}{*}{0.003} \\
\hline Nonsmoker & $100.0(51)$ & $87.7(64)$ & $78.7(37)$ & \\
\hline Smoker & $0.0(0)$ & $12.3(9)$ & $21.3(10)$ & \\
\hline \multicolumn{4}{|l|}{ Body mass index, \% (No.) } & \multirow[t]{3}{*}{0.396} \\
\hline$<30 \mathrm{~kg} / \mathrm{m}^{2}$ & $58.8(30)$ & $48.0(35)$ & $46.8(22)$ & \\
\hline$\geq 30 \mathrm{~kg} / \mathrm{m}^{2}$ & $41.2(21)$ & $52.1(38)$ & $53.2(25)$ & \\
\hline \multicolumn{5}{|c|}{ Preoperative diagnoses, $\%\left(\mathrm{No}^{\mathrm{b}}\right.$} \\
\hline Myocardial infarction & $0.0(0)$ & $1.37(1)$ & $4.3(2)$ & 0.262 \\
\hline Diabetes & $0.0(0)$ & $5.5(4)$ & $17.0(8)$ & 0.003 \\
\hline Arthritis & $0.0(0)$ & $17.8(13)$ & 36.2 (17) & $<\mathbf{0 . 0 0 1}$ \\
\hline Hypertension & $0.0(0)$ & $27.4(20)$ & $55.3(26)$ & $<\mathbf{0 . 0 0 1}$ \\
\hline Neurological disease & $0.0(0)$ & $0.0(0)$ & $4.3(2)$ & 0.069 \\
\hline Peripheral vascular disease & $0.0(0)$ & $1.4(1)$ & $0.0(0)$ & 0.509 \\
\hline Malignancy & $0.0(0)$ & $0.0(0)$ & $31.9(15)$ & $<0.001$ \\
\hline
\end{tabular}

Abbreviation: SD, standard deviation.

${ }^{\mathrm{a}} P$ value was calculated for each category using multivariate linear regression (continuous) or $\chi^{2}$ analysis (categorical).

${ }^{\mathrm{b}}$ There were no patients in our study with a recorded medical history of acquired immunodeficiency syndrome, paraplegia, congestive heart failure, metastatic disease, liver disease, renal failure, chronic obstructive pulmonary disease, or gastrointestinal bleeds.

zation of the transforaminal space (to the inferior pedicle) and nerve roots was accomplished before preparing the endplates. To optimize lumbar lordosis, surgeon preference guided the prefilling and backfilling of the disc space before placing the interbody. Guidewires were removed for percutaneous pedicle screw placement. Instrumentation positioning was verified with fluoroscopic guidance. Finally, the pedicle screws were connected with rods and screw sets.

\section{RESULTS}

\section{Baseline Demographic and Perioperative Characteristics}

From May 2015 and February 2019, 171 MIS TLIF patients underwent a primary or revision, 1or 2-level MIS TLIF. A total of 51 patients had no comorbidities $(\mathrm{CCI}=0), 73$ had a mild comorbidity burden $(\mathrm{CCI}=1-2)$, and 47 had a moderate $(\mathrm{CCI} \geq$ $3)$. The cohort CCI subgroups had a statistically significant association for age (Table 1). Mean subgroup age increased with comorbidity burden $(\mathrm{CCI}=0: 40.9$ years; $\mathrm{CCI}=1-2: 51.7$ years; $\mathrm{CCI} \geq$ 3: 60.4 years, $P<0.001)$. Statistically significant differences were observed for smoking status, diabetes, arthritis, hypertension, and malignancy. Those with no comorbidity $(\mathrm{CCI}=0)$ burden did not smoke (nonsmokers: $100.0 \%, \mathrm{n}=51$ ), followed by those with a mild comorbidity $(\mathrm{CCI}=1-2)$ burden (nonsmokers: $87.7 \%, \mathrm{n}=64$ ), and with those who held the highest comorbidity burden having the lowest fraction of nonsmokers (nonsmokers: 78.7\%, $\mathrm{n}=37$ ). The percentage of preoperative diagnoses within each subgroup increased with comorbidity burden severity. Among the subgroups, the percentage of patients with diabetes was $0.0 \%$ (0) for the no comorbidity subgroup $(\mathrm{CCI}=0), 5.5 \%$ (4) for the moderate comorbidity subgroup $(\mathrm{CCI}=1-2)$, and $17.0 \%$ (8) for those with the most severe comorbidity burden $(P=0.003)$. No patients had arthritis within the no comorbidity subgroup $(\mathrm{CCI}=0)$, $17.8 \%$ (13) had arthritis in the moderate comorbidity subgroup (CCI $=1-2$ ), and $36.2 \%$ (17) had arthritis in the most severely comorbid group burden $(P<0.001)$. Among the subgroups, the fraction of those with hypertension increased with CCI severity $(\mathrm{CCI}=0: 0.0 \%[0] ; \mathrm{CCI}=1-2: 27.4 \%$ [20]; CCI $\geq 3: 55.3 \%$ [26], $P<0.001)$. Neither of the lesser comorbidity burden subgroups had any patients with malignancies, though the most severe comorbidity burden subgroup had $31.9 \%$ (15) with a past malignancy $(P<0.001)$. There were no statistically significant perioperative characteristic differences between CCI groups for number of fusion levels, operative time duration, EBL, length of stay, or discharge day (Table 2). There were no significant differences in the rate of complications intraoperatively and postoperatively among CCI subgroups. The most common complication was postoperative nausea and vomiting $(4.6 \%)$. None of the reported complications required a return to the operating room, and all patients had resolution of their symptoms before discharge. 
Table 2. Perioperative outcomes by Charlson Comorbidity Index $(\mathrm{CCl})$ group.

\begin{tabular}{|c|c|c|c|c|}
\hline Characteristic & $\mathrm{CCI}=0(\mathrm{~N}=51)$ & $\mathrm{CCI}=1-2(\mathrm{~N}=73)$ & $\mathrm{CCI} \geq 3(\mathrm{~N}=47)$ & $P$ Value $^{\mathrm{a}}$ \\
\hline Number of fusion levels, \% (No.) & & & & 0.637 \\
\hline 1 level & $90.2(46)$ & $94.5(69)$ & $93.6(44)$ & \\
\hline 2 level & $9.8(5)$ & $5.5(4)$ & $6.4(3)$ & \\
\hline Operative time, mean $\pm \mathrm{SD}$, min & $128.7 \pm 27.8$ & $128.2 \pm 31.8$ & $131.8 \pm 30.4$ & 0.808 \\
\hline Estimated blood loss, mean $\pm \mathrm{SD}, \mathrm{mL}$ & $51.7 \pm 26.5$ & $61.5 \pm 75.6$ & $49.6 \pm 26.6$ & 0.416 \\
\hline Length of stay, mean $\pm \mathrm{SD}, \mathrm{h}$ & $29.0 \pm 19.5$ & $33.3 \pm 19.5$ & $34.7 \pm 18.2$ & 0.307 \\
\hline Discharge date, $\%$ (No.) & & & & 0.228 \\
\hline POD 0 & $22.5(12)$ & $12.3(9)$ & $6.4(3)$ & \\
\hline POD 1 & $52.9(27)$ & $63.0(46)$ & $59.6(28)$ & \\
\hline POD 2 & $19.6(10)$ & $16.4(12)$ & $23.4(11)$ & \\
\hline POD $3+$ & $3.9(2)$ & $8.2(6)$ & $10.6(5)$ & \\
\hline \multicolumn{5}{|l|}{ Complications, \% (No.) } \\
\hline Urinary retention & $0.0(0)$ & $1.37(1)$ & $2.13(1)$ & 0.606 \\
\hline Atelectasis & $0.0(0)$ & $1.37(1)$ & $0.0(0)$ & 0.509 \\
\hline Nausea and vomiting & $3.92(2)$ & $2.74(2)$ & $8.51(4)$ & 0.328 \\
\hline Postoperative anemia & $0.0(0)$ & $1.37(1)$ & $0.0(0)$ & 0.509 \\
\hline Altered mental status & $0.0(0)$ & $1.37(1)$ & $0.0(0)$ & 0.509 \\
\hline Deep vein thrombosis & $0.0(0)$ & $0.0(0)$ & $2.13(1)$ & 0.265 \\
\hline Orthostatic hypotension & $0.0(0)$ & $1.37(1)$ & $0.0(0)$ & 0.509 \\
\hline Hyponatremia & $0.0(0)$ & $1.37(1)$ & $0.0(0)$ & 0.509 \\
\hline
\end{tabular}

Abbreviations: POD, postoperative day; SD, standard deviation.

${ }^{\text {a }} P$ value was calculated for each category using multivariate linear regression (continuous) or $\chi^{2}$ analysis (categorical).

\section{Outcome Comparisons by $\mathrm{CCl}$}

PROMs were observed to have statistically significant associations with CCI subgroups for at least 1 of the evaluated timepoints for VAS back pain levels,
VAS leg pain levels, ODI pain levels, and PROMIS PF (Table 3). Only ODI (CCI $=0: 47.2 ; \mathrm{CCI}=1-2$ : 45.2; CCI $\geq 3$ : 37.38; $P=0.015)$ and PROMIS PF $(\mathrm{CCI}=0: 36.0 ; \mathrm{CCI}=1-2: 33.3 ; \mathrm{CCI} \geq 3: 36.3 ; P=$

Table 3. Patient-reported outcome comparisons by Charlson Comorbidity Index (CCI) status. Boldface indicates statistical significance. Italics indicate supplemental $P$ values related to assess if follow-up rate at each timepoint is significant.

\begin{tabular}{|c|c|c|c|c|c|c|c|c|}
\hline & $\begin{array}{c}\mathrm{CCI}=\mathbf{0} \\
\text { mean } \pm \mathrm{SD} \text { (No.) }\end{array}$ & $\mathbf{F} / \mathbf{U}, \%$ & $\begin{array}{c}\mathrm{CCI}=1-2 \\
\text { mean } \pm \mathrm{SD}(\text { No.) }\end{array}$ & $\mathbf{F} / \mathbf{U}, \%$ & $\begin{array}{c}\mathrm{CCI} \geq 3, \\
\text { mean } \pm \mathrm{SD} \text { (No.) }\end{array}$ & F/U, \% & $P$ Value $^{\mathrm{a}}$ & $P$ Value $^{\mathrm{b}}$ \\
\hline \multicolumn{9}{|l|}{ VAS back time } \\
\hline Preoperative & $7.01 \pm 2.03(50)$ & & $6.68 \pm 2.48(71)$ & & $6.30 \pm 2.44(45)$ & & 0.331 & \\
\hline $6 \mathrm{wk}$ & $3.86 \pm 2.94(44)$ & 86.3 & $4.65 \pm 2.48(64)$ & 87.5 & $3.59 \pm 2.56(42)$ & 88.2 & 0.099 & 0.955 \\
\hline $12 \mathrm{wk}$ & $3.41 \pm 2.95(41)$ & 80.4 & $4.23 \pm 2.54(60)$ & 81.9 & $3.19 \pm 2.66(43)$ & 86.3 & 0.121 & 0.713 \\
\hline $6 \mathrm{mo}$ & $2.66 \pm 2.71(40)$ & 78.4 & $4.41 \pm 2.80(56)$ & 76.4 & $3.04 \pm 2.50(39)$ & 76.5 & 0.004 & 0.960 \\
\hline $1 y$ & $2.00 \pm 2.35(21)$ & 43.1 & $4.33 \pm 3.03(36)$ & 50.0 & $2.28 \pm 2.28(23)$ & 49.0 & 0.002 & 0.736 \\
\hline \multicolumn{9}{|l|}{ VAS leg } \\
\hline Preoperative & $5.77 \pm 2.87(50)$ & & $5.45 \pm 3.17(71)$ & & $5.74 \pm 3.00(45)$ & & 0.821 & \\
\hline $6 \mathrm{wk}$ & $2.73 \pm 3.12(44)$ & 86.3 & $3.57 \pm 2.82(64)$ & 87.5 & $3.03 \pm 2.98(42)$ & 88.2 & 0.334 & 0.955 \\
\hline $12 \mathrm{wk}$ & $2.30 \pm 2.95(41)$ & 80.4 & $2.94 \pm 2.72(60)$ & 81.9 & $2.94 \pm 2.98(44)$ & 88.2 & 0.484 & 0.522 \\
\hline $6 \mathrm{mo}$ & $1.65 \pm 2.36(40)$ & 78.4 & $3.12 \pm 2.97(56)$ & 76.4 & $2.42 \pm 2.67(39)$ & 76.5 & 0.035 & 0.960 \\
\hline $1 \mathrm{y}$ & $1.78 \pm 2.16(21)$ & 43.1 & $3.48 \pm 3.55(36)$ & 50.0 & $2.38 \pm 2.83(23)$ & 49.0 & 0.107 & 0.736 \\
\hline \multicolumn{9}{|l|}{ ODI } \\
\hline Preoperative & $47.20 \pm 17.26(50)$ & & $45.16 \pm 19.21(71)$ & & $37.38 \pm 13.78(45)$ & & 0.015 & \\
\hline $6 \mathrm{wk}$ & $34.24 \pm 22.66(44)$ & 86.3 & $39.58 \pm 18.90(64)$ & 87.5 & $33.95 \pm 21.84(43)$ & 90.2 & 0.283 & 0.822 \\
\hline $12 \mathrm{wk}$ & $27.90 \pm 21.16(41)$ & 80.4 & $33.53 \pm 19.20(62)$ & 84.7 & $30.16 \pm 17.76(44)$ & 88.2 & 0.336 & 0.548 \\
\hline $6 \mathrm{mo}$ & $17.95 \pm 18.56(40)$ & 78.4 & $31.42 \pm 21.63(57)$ & 77.8 & $21.02 \pm 15.40(39)$ & 76.5 & 0.002 & 0.971 \\
\hline $1 \mathrm{y}$ & $14.57 \pm 15.42(21)$ & 43.1 & $28.91 \pm 23.77(36)$ & 50.0 & $20.15 \pm 18.79(23)$ & 49.0 & 0.083 & 0.736 \\
\hline \multicolumn{9}{|l|}{ SF-12 Physical } \\
\hline Preoperative & $29.75 \pm 7.55(49)$ & & $30.07 \pm 8.48(67)$ & & $29.80 \pm 7.76(42)$ & & 0.973 & \\
\hline $6 \mathrm{wk}$ & $32.11 \pm 8.36(44)$ & 86.3 & $29.89 \pm 8.23(57)$ & 79.2 & $31.22 \pm 9.08(41)$ & 80.4 & 0.421 & 0.584 \\
\hline $12 \mathrm{wk}$ & $36.19 \pm 10.27(38)$ & 74.5 & $33.74 \pm 10.09(57)$ & 77.8 & $35.31 \pm 10.81(37)$ & 74.5 & 0.509 & 0.884 \\
\hline $6 \mathrm{mo}$ & $42.10 \pm 11.22(35)$ & 68.6 & $37.02 \pm 12.68(47)$ & 65.3 & $38.67 \pm 12.77(32)$ & 62.8 & 0.180 & 0.821 \\
\hline $1 \mathrm{y}$ & $45.00 \pm 11.44(19)$ & 39.2 & $38.14 \pm 12.18(45)$ & 65.3 & $39.05 \pm 9.71(25)$ & 51.0 & 0.087 & 0.016 \\
\hline \multicolumn{9}{|l|}{ PROMIS PF } \\
\hline Preoperative & $35.95 \pm 7.02(51)$ & & $33.31 \pm 6.62(73)$ & & $36.29 \pm 3.91(47)$ & & 0.014 & \\
\hline $6 \mathrm{wk}$ & $37.77 \pm 6.77(39)$ & 76.5 & $34.89 \pm 6.62(52)$ & 70.8 & $36.43 \pm 7.83(37)$ & 76.5 & 0.154 & 0.705 \\
\hline $12 \mathrm{wk}$ & $42.62 \pm 9.28(30)$ & 58.8 & $39.27 \pm 7.86(48)$ & 66.7 & $38.96 \pm 6.76(32)$ & 66.7 & 0.129 & 0.617 \\
\hline $6 \mathrm{mo}$ & $46.74 \pm 7.98(32)$ & 64.7 & $42.52 \pm 8.82(42)$ & 58.3 & $41.87 \pm 8.04(32)$ & 62.8 & 0.041 & 0.756 \\
\hline $1 \mathrm{y}$ & $48.20 \pm 10.39(21)$ & 45.1 & $42.37 \pm 10.99(41)$ & 58.3 & $43.91 \pm 5.92(24)$ & 51.0 & 0.086 & 0.342 \\
\hline
\end{tabular}

Abbreviations: F/U, follow up; ODI, Oswestry Disability Index; PROMIS PF, Patient-Reported Outcomes Measurement Information System Physical Function; SF-12, Short Form-12; VAS, visual analog scale.

${ }^{\text {a } P}$ value was calculated using linear regression to compare scores at each timepoint.

${ }^{\mathrm{b}} P$ value was calculated using $\chi^{2}$ to compare follow-up rates with preoperative (No.) among each CCI subgroup. 
Table 4. Achievement of minimal clinically important difference (MCID), percentage (No./total). Boldface indicates statistical significance. ${ }^{a}$

\begin{tabular}{|c|c|c|c|c|c|}
\hline & Preop to $6 \mathrm{wk}$ & Preop to $3 \mathrm{mo}$ & Preop to $6 \mathrm{mo}$ & Preop to $12 \mathrm{mo}$ & Overall met MCID \\
\hline \multicolumn{6}{|l|}{ VAS back } \\
\hline $\mathrm{CCI}=0$ & $82.4(42 / 51)$ & $90.2(46 / 51)$ & $90.2(46 / 51)$ & $96.1(49 / 51)$ & $100.0(51 / 51)$ \\
\hline $\mathrm{CCI}=1-2$ & $63.0(46 / 73)$ & $67.1(49 / 73)$ & $71.2(52 / 73)$ & $83.6(61 / 73)$ & $90.4(66 / 73)$ \\
\hline $\mathrm{CCI} \geq 3$ & $72.3(34 / 47)$ & $78.7(37 / 47)$ & $83.0(39 / 47)$ & $93.6(44 / 47)$ & $97.9(46 / 47)$ \\
\hline$P$ value $\dagger$ & 0.063 & 0.010 & 0.029 & 0.046 & 0.028 \\
\hline \multicolumn{6}{|l|}{ VAS leg } \\
\hline $\mathrm{CCI}=0$ & $74.5(38 / 51)$ & $76.5(39 / 51)$ & $78.4(40 / 51)$ & $90.2(46 / 51)$ & $94.1(48 / 51)$ \\
\hline $\mathrm{CCI}=1-2$ & $60.3(44 / 73)$ & $67.1(49 / 73)$ & $60.3(44 / 73)$ & $76.7(56 / 73)$ & $87.7(64 / 73)$ \\
\hline $\mathrm{CCI} \geq 3$ & $72.3(34 / 47)$ & $68.1(32 / 47)$ & $76.6(36 / 47)$ & $89.4(42 / 47)$ & $97.9(46 / 47)$ \\
\hline$P$ valuet & 0.183 & 0.499 & 0.050 & 0.067 & 0.103 \\
\hline \multicolumn{6}{|l|}{ ODI } \\
\hline $\mathrm{CCI}=0$ & $60.8(31 / 51)$ & $62.8(32 / 51)$ & $86.3(44 / 51)$ & $92.2(47 / 51)$ & $94.1(48 / 51)$ \\
\hline $\mathrm{CCI}=1-2$ & $42.5(31 / 73)$ & $52.1(38 / 73)$ & $56.2(41 / 73)$ & $80.8(59 / 73)$ & $84.9(62 / 73)$ \\
\hline $\mathrm{CCI} \geq 3$ & $46.8(22 / 47)$ & $48.9(23 / 47)$ & $68.1(32 / 47)$ & $85.1(40 / 47)$ & $89.4(42 / 47)$ \\
\hline$P$ valuet & 0.124 & 0.340 & 0.002 & 0.213 & 0.275 \\
\hline \multicolumn{6}{|l|}{ SF-12 PCS } \\
\hline $\mathrm{CCI}=0$ & $68.6(35 / 51)$ & $60.8(31 / 51)$ & $60.8(31 / 51)$ & $33.3(17 / 51)$ & $92.2(47 / 51)$ \\
\hline $\mathrm{CCI}=1-2$ & $57.5(42 / 73)$ & $60.3(44 / 73)$ & $49.3(36 / 73)$ & $53.4(39 / 73)$ & $86.3(63 / 73)$ \\
\hline $\mathrm{CCI} \geq 3$ & $57.5(27 / 47)$ & $53.2(25 / 47)$ & $51.1(24 / 47)$ & $46.8(22 / 47)$ & $80.9(38 / 47)$ \\
\hline$P$ valuet & 0.395 & 0.687 & 0.426 & 0.085 & 0.260 \\
\hline \multicolumn{6}{|l|}{ PROMIS } \\
\hline $\mathrm{CCI}=0$ & $70.6(36 / 51)$ & $58.8(30 / 51)$ & $60.8(31 / 51)$ & $41.2(21 / 51)$ & $92.2(47 / 51)$ \\
\hline $\mathrm{CCI}=1-2$ & $68.5(50 / 73)$ & $65.8(48 / 73)$ & $57.5(42 / 73)$ & $56.2(41 / 73)$ & $91.8(67 / 73)$ \\
\hline $\mathrm{CCI} \geq 3$ & $70.2(33 / 47)$ & $66.0(31 / 47)$ & $66.0(31 / 47)$ & $51.1(24 / 47)$ & $91.5(43 / 47)$ \\
\hline$P$ valuet & 0.964 & 0.683 & 0.653 & 0.258 & 0.993 \\
\hline
\end{tabular}

Abbreviations: CCI, Charlson Comorbidity Index; ODI, Oswestry Disability Index; PROMIS, Patient-Reported Outcomes Measurement Information System; SF-12, Short Form-12; VAS, visual analog scale.

${ }^{\mathrm{a}}$ The following MCID values were derived from Copay et $\mathrm{al}^{11}$ : VAS back $=1.2$, VAS leg $=1.6$, ODI $=12.8, \mathrm{SF}-12=4.0$. The PROMIS MCID value was derived from Hung et al: PROMIS Physical Function $=4.5 .^{11-13}$

${ }^{\mathrm{b}} P$ value was calculated for each category using $\chi^{2}$ analysis.

0.014) were observed to have statistically significant associations with CCI subgroups. No PROMs were observed to have statistically significant associations for either the 6-week or the 12-week timepoint evaluations. Except for SF-12, all PROMs had statistically significant associations at the 6-month timepoint. At 6 months, VAS back pain levels were the worst among those with a moderate comorbidity burden $(\mathrm{CCI}=0: 2.66 ; \mathrm{CCI}=1-2: 4.41 ; \mathrm{CCI} \geq 3: 3.04$; $P=0.004)$. VAS leg pain levels were also the most severe among those with moderate comorbidity burdens $(\mathrm{CCI}=0$ : 1.65 ; $\mathrm{CCI}=1-2: 3.12 ; \mathrm{CCI} \geq 3$ : $2.42 ; P=0.035)$. Those with a moderate comorbidity burden also had the most severe ODI scores $(\mathrm{CCI}=0$ : 17.9; $\mathrm{CCI}=1-2$ : 31.4 ; $\mathrm{CCI} \geq 3$ : $15.4 ; P=0.002)$. Finally, we observed that PROMIS PF score decreased with comorbidity burden severity $(\mathrm{CCI}=$ $0: 46.7 ; \mathrm{CCI}=1-2: 42.5 ; \mathrm{CCI} \geq 3: 41.9 ; P=0.041)$. By the 1-year timepoint evaluation, VAS back pain was the only PROM that demonstrated a statistically significant association with comorbidity subgroup $(\mathrm{CCI}=0: 2.0 ; \mathrm{CCI}=1-2: 4.3 ; \mathrm{CCI} \geq 3: 2.3 ; P=0.002)$. In comparison with the preoperative evaluation, follow-up rates varied by timepoints, ranging from $70.5 \%$ to $90.2 \%$ at 6 weeks, $58.8 \%$ to $88.2 \%$ at 12 weeks, $58.3 \%$ to $78.4 \%$ at 6 months, and $39.2 \%$ to $65.3 \%$ at 1 year. Among the CCI subgroups, only the
SF-12 PCS 1-year follow up had statistically significant differences in follow-up proportions $(P=0.016)$.

\section{MCID Achievement by $\mathrm{CCl}$}

Only VAS back pain and ODI were observed to have statistically significant differences among subgroups for MCID achievement at any of the evaluated timepoints. For VAS back pain at 3 months, those with a moderate comorbidity burden had the lowest MCID achievement $(\mathrm{CCI}=0: 90.2 \%$; $\mathrm{CCI}=1-2: 67.1 \% ; \mathrm{CCI} \geq 3: 78.7 \% ; P=0.010)$. At 6 months, those with moderate comorbidity burdens also had the lowest MCID attainment for VAS back pain $(\mathrm{CCI}=0: 90.2 \%$; CCI $=1-2: 71.2 \%$; CCI $\geq 3$ : $83.0 \% ; P=0.029)$ as well as the lowest MCID achievement for ODI (CCI $=0: 86.3 \%$; CCI $=1-2$ : $56.2 \%$; CCI $\geq 3: 68.1 \% ; P=0.002)$. VAS back pain level was the only PROM to demonstrate statistically significant differences in MCID achievement at 1 year $(\mathrm{CCI}=0: 96.1 \% ; \mathrm{CCI}=1-2: 83.6 \% ; \mathrm{CCI} \geq 3: 93.6 \%$; $P=0.046)$ and when considering any MCID achievement at any timepoint (CCI $=0: 100.0 \%$; $\mathrm{CCI}=1-2: 90.4 \% ; \mathrm{CCI} \geq 3: 97.9 \% ; P=0.028)$. No difference in the rate of achieving MCID was observed among comorbidity subgroups for VAS leg, SF-12 PCS, and PROMIS PF (Table 4). 


\section{DISCUSSION}

The extent to which comorbidity burden influences the postsurgical outcomes of spine surgery is a subject of continued inquiry for orthopaedic researchers. Numerous researchers have focused on the possible association between preoperative comorbidity burden and intraoperative complications. The literature is mixed when discussing the association various comorbidities have on postoperative outcome instruments. ${ }^{14-18}$ Although previous researchers have assessed the influence of CCI after MIS TLIF with a single PRO, ${ }^{10}$ this study adds to previous investigations by analyzing this patient population with multiple PROs and in evaluating MCID achievement. As MIS procedures continue to develop, the literature is still scarce regarding the potential association between preoperative comorbidity and postoperative outcome measures. While further investigation may be required to examine mechanisms that underlie fluctuations of each PROM, the results of this study demonstrate that MIS TLIF is associated with improvement in numerous PROMs regardless of a patient's preoperative CCI.

Nevertheless, it is important for surgeons to be aware of each patient's comorbidity burden and how the comorbidities relate to specific postoperative outcomes. In our analysis of 171 MIS TLIF patients, we analyzed patient subgroups based on previously established mortality threshold subgroups by Charlson et al, ${ }^{19}$ eg, 0 points (no comorbidities), 1-2 points (mild CCI), $\geq 3$ points (moderate CCI). These subgroups that reflect differences in mortality have been validated for the past 3 decades. ${ }^{20-22}$ The CCI is now used extensively in orthopaedic literature. ${ }^{23}$ While some contend that using the CCI is adequate when measuring complications after spine surgery, ${ }^{14,15}$ it is important to recognize that the index was developed in the early 1980s among a nonsurgical patient population in New York. ${ }^{19}$ Although the CCI was constructed to predict 1-year mortality, it also includes comorbidity burdens that have been demonstrated to specifically affect 1-year survival, eg, acquired immunodeficiency syndrome or metastatic solid tumors. Furthermore, the CCI does not consider comorbidities that have been known to affect spine surgery outcomes such as depressive symptoms, osteoarthritis, and rheumatoid arthristis. ${ }^{1}$ Understandably, the ability for the CCI to be used among studies that investigate orthopaedic health-related quality of life outcomes has been questioned. ${ }^{16,17}$

Our study is aligned with previous studies that have observed spine surgery patients with a higher comorbidity burden to be older, to smoke, and to have been diagnosed with diabetes, arthritis, hypertension, or a malignancy. ${ }^{6,18,24-26}$ As these previous studies have highlighted, to improve clinical outcomes, it is imperative to evaluate patients with comorbidities. While other studies have more narrowly focused on specific PROMs or complications after lumbar surgery, ${ }^{27}$ there is a scarcity of research focused on the influence of increased comorbidity burden on achieving a well-known metric such as MCID among multiple PROMs.

Overall, our findings suggest that increasing comorbidity does not necessarily result in worse physical function at 1 year. Spine literature is mixed regarding the influence of comorbidity burden on postoperative physical function outcomes. For example, Slover et $\mathrm{al}^{6}$ observed statistically significant preoperative and postoperative influences of comorbidity on physical function as measured by the Short Form-36 (SF-36). ${ }^{28}$ In another study, Nerland et $\mathrm{al}^{29}$ observed no statistical significance with regard to the presence of preoperative nonspecific comorbidity with both univariate $(P=0.079)$ and multivariate analyses $(P=0.294)$. Our comparison with Nerland et $\mathrm{al}^{29}$ is limited in that their primary investigated outcome was ODI, and their study population was drawn from the Norwegian Registry for Spine Surgery, which is based on a universal health care system. At least 1 other retrospective analysis that examined CCI subgroups demonstrated no statistically significant correlation with increased CCI and postoperative outcomes such as SF-36. ${ }^{16}$ This latter study was, however, focused on cervical surgery, and it investigated Neck Disability Index (NDI) and SF-36 PCS. Regardless of the PROM investigated in either of the studies, neither investigated MCID achievement. To our knowledge, the literature is exceedingly limited in its investigation on the influence of comorbidity burden on physical function MCID achievement.

We observed that, although there were preoperative differences in disability as assessed by ODI during the preoperative period, these differences only resurfaced at 6 months and were not apparent at 1 year. Our ODI findings agree with other studies that have realized statistically significant preoperative differences among patients with different levels 
of comorbidity burden. Several studies have suggested that a lack of ODI score improvement is associated with systemic disease independent of any presence of comorbidity. ${ }^{15,29,30}$ While ODI is designed as a disease-specific survey, comorbidity burdens have been observed to affect it because functional loss and pain levels can have etiologies that are multifactoral. ${ }^{6}$ By 1 year, we observed no statistically significant differences among patients. While this differs from Slover et al, ${ }^{6}$ who observed statistically significant differences among patients with different levels of comorbidity, this comparison is limited in that they did not investigate with the CCI.

Finally, our results were mixed regarding the pain levels that patients experience preoperatively and postoperatively. We observed that neither VAS back nor VAS leg pain had a statistically significant difference among comorbidity subgroups at the preoperative evaluation. While back pain severity levels appeared to differ at the 1-year timepoint by comorbidity subgroup, leg pain did not have a statistically significant association with comorbidity level. One of the primary indications for lumbar fusion include radiculopathy symptoms such as leg pain. ${ }^{31,32}$ Hence, it is understandable that successful lumbar fusion might have resulted in no statistically significant difference in leg pain among our subgroups. While the etiologies that underlie leg pain can be diverse, lower back pain has specifically been demonstrated to have multifactorial causes associated with increased patient comorbidity burdens. The increased presence of lower back pain has been associated with patient comorbidities such as age, ${ }^{33}$ anxiety, ${ }^{34} \mathrm{BMI},{ }^{35}$ depression, ${ }^{34}$ female gender, ${ }^{36,37}$ job dissatisfaction, ${ }^{38}$ low education, ${ }^{39}$ psychological stress, ${ }^{34}$ smoking, ${ }^{40,41}$ sedentary lifestyle, ${ }^{42}$ strenuous physical work, ${ }^{42}$ and worker's compensation. ${ }^{43,44}$ With these potential associations, it appears possible that, compared with those with no comorbidities, those with a comorbid burden might still experience lower back pain even after lumbar fusion. Further subanalyses are required to discover what comorbidities are most associated with persistent back pain after MIS TLIF.

\section{Limitations}

While this study adds to other studies that have noted a questionable applicability of the CCI regarding spine surgery outcomes, several limitations must be acknowledged. First, the retrospective nature of this study makes it susceptible to a selection bias. Other selection biases may have occurred due to the nature of postoperative recovery follow up. As a result of our study's exclusion of patients that were undergoing surgery for infectious, malignant, or traumatic etiologies, our results may not be generalizable to these groups. Additionally, surgeon discretion was used on an individual basis when screening patients to account for other possible comorbidities, surgical history, increased age, extremes of BMI, increased risks for nausea and vomiting, personal independence, and caretaker requirements. Although patient selection was used to optimize postsurgical outcomes, this may have also contributed to a selection bias toward more healthy patients and improved outcomes. We observed a substantial loss to follow up, most prominently for the SF-12 instrument at the 1-year postoperative timepoint. This follow-up rate ranged from $39.2 \%$ to $58.3 \%$. Although the SF-12 physical score 1-year follow up had statistically significant differences in follow-up proportions, in this case, the CCI $\geq 3$ subgroup had the best follow-up rate, and the overall SF-12 physical instrument mean score differences were nonetheless still insignificant $(P=0.087)$. While some studies have observed that elevated CCI is associated with an increased likelihood of becoming lost to follow up, ${ }^{45}$ others have observed no clear trend. ${ }^{46}$ There was no clear overall pattern regarding our follow-up proportions among CCI subgroups. Each subgroup had the highest proportion of patients following up within any instrument timepoint score collection exactly 6 times. There were 2 postoperative timepoints in which 2 CCI subgroups tied for the follow-up proportion, but even the tying subgroups varied. During the PROMIS PF 6-week evaluation, the $\mathrm{CCI}=0$ and the $\mathrm{CCI}=1-2$ subgroups tied but at the following PROMIS PF timepoint, it was the CCI = $1-2$ and the CCI $\geq 3$ subgroups that had the best follow-up rate. While losses to follow up are notorious for their contribution to selection biasregardless of the 1 timepoint which had a significant follow-up difference among CCI groups - our overall varied follow-up rates make it difficult to determine whether CCI was a valid risk factor regarding follow up. One other limitation may be related to our use of only 1 MCID value for each instrument. To our knowledge, based on literature review, we used MCID values that most closely reflected our patient population that underwent 
lumbar fusion surgery for degenerative spine pathologies. Other studies, including prospective investigational device exemption studies, have used MCID values for VAS pain and ODI of 18-19 mm and 10.0, respectively. ${ }^{47,48}$ MCID values that are used do, however, vary considerably. One review found MCID ranges for ODI from 5.3 to 14.9, for VAS back pain from 2.1 to 3.8 , VAS leg pain from 2.4 to $5.0, \mathrm{SF}-12$ PCS from 2.5 to 8.8 , and for SF-12 MCS from 3.6 to $10.1{ }^{49}$ Increased or decreased symptom severity might have changed the likelihood of patients returning to clinic. Relatedly, because many of the assessed outcomes were dependent on patient response, overreporting, underreporting, or misreporting may have impacted our results. This study is also limited in that it did not conduct further subanalyses to discern whether age or other comorbidities might be most associated with persistent back pain after surgery. This study is also limited in that we did not have data from selfreported comorbidity indices such as the selfadministered comorbidity questionnaire (SCQ) developed by Sangha et al. ${ }^{50}$ The SCQ has been observed to be useful due to its ability to consider other psychiatric and psychological comorbidities. Further investigation is necessary to identify wither the SCQ is more associated with MIS TLIF outcomes.

\section{CONCLUSIONS}

In this study, we assessed the preoperative state and postoperative recovery of patients as they varied by CCI classification. Regardless of the CCI subgroup, we observed a similar proportion of patients were able to attain MCID for leg pain, overall physical function, and with disability. It should be noted that there was decreased follow up through the 1-year postoperative period. This study established that patients with higher indices of comorbidity burden as measured by CCI are not necessarily less likely to experience a significant clinical improvement. Hence, this study demonstrates that MIS TLIF can have substantial clinical benefit for patients of various comorbidity states.

\section{REFERENCES}

1. Slover J, Abdu WA, Hanscom B, Lurie J, Weinstein JN. Can condition-specific health surveys be specific to spine disease? An analysis of the effect of comorbidities on baseline condition-specific and general health survey scores. Spine.
2006;31(11):1265-1271. doi:10.1097/01.brs.0000217635.67693. 40

2. Villavicencio AT, Burneikiene S, Roeca CM, Nelson EL, Mason A. Minimally invasive versus open transforaminal lumbar interbody fusion. Surg Neurol Int. 2010;1:12. doi:10. 4103/2152-7806.63905

3. Katz JN, Stucki G, Lipson SJ, Fossel AH, Grobler LJ, Weinstein JN. Predictors of surgical outcome in degenerative lumbar spinal stenosis. Spine. 1999;24(21):2229-2233.

4. Gijsen R, Hoeymans N, Schellevis FG, Ruwaard D, Satariano WA, van den Bos GAM. Causes and consequences of comorbidity: a review. J Clin Epidemiol. 2001;54(7):661-674.

5. Lee KH, Yue WM, Yeo W, Soeharno H, Tan SB. Clinical and radiological outcomes of open versus minimally invasive transforaminal lumbar interbody fusion. Eur Spine $J$. 2012;21(11):2265-2270.

6. Slover J, Abdu WA, Hanscom B, Weinstein JN. The impact of comorbidities on the change in Short-Form 36 and Oswestry scores following lumbar spine surgery. Spine. 2006;31(17):1974-1980.

7. Li G, Patil CG, Lad SP, Ho C, Tian W, Boakye M. Effects of age and comorbidities on complication rates and adverse outcomes after lumbar laminectomy in elderly patients. Spine. 2008;33(11):1250-1255.

8. Fanuele JC, Birkmeyer NJO, Abdu WA, Tosteson TD, Weinstein JN. The impact of spinal problems on the health status of patients: have we underestimated the effect? Spine. 2000;25(12):1509-14.

9. Deyo RA, Mirza SK, Martin BI. Error in trends, major medical complications, and charges associated with surgery for lumbar spinal stenosis in older adults. JAMA. 2011;306(10):1088. doi:10.1001/jama.2011.1300

10. Parrish JM, Jenkins NW, Hrynewycz NM, Brundage TS, Yoo JS, Singh K. The impact of comorbidity burden on postoperative PROMIS Physical Function following minimally invasive transforaminal lumbar interbody fusion. Clin Spine Surg. 2020;33(6):E294-E298. doi:10.1097/BSD.0000000000000 934

11. Copay AG, Glassman SD, Subach BR, Berven S, Schuler TC, Carreon LY. Minimum clinically important difference in lumbar spine surgery patients: a choice of methods using the Oswestry Disability Index, Medical Outcomes Study questionnaire Short Form 36, and pain scales. Spine $J$. 2008;8(6):968-974.

12. Parker SL, Adogwa O, Mendenhall SK, et al. Determination of minimum clinically important difference (MCID) in pain, disability, and quality of life after revision fusion for symptomatic pseudoarthrosis. Spine $J$. 2012;12(12):1122-1128.

13. Hung M, Saltzman CL, Kendall R, et al. What are the MCIDs for PROMIS, NDI, and ODI instruments among patients with spinal conditions? Clin Orthop Relat Res. 2018;476(10):2027-2036.

14. Arrigo RT, Kalanithi P, Cheng I, et al. Charlson score is a robust predictor of 30-day complications following spinal metastasis surgery. Spine. 2011;36(19):E1274-E1280.

15. Whitmore RG, Stephen JH, Vernick C, et al. ASA grade and Charlson Comorbidity Index of spinal surgery patients: correlation with complications and societal costs. Spine J. 2014;14(1):31-38.

16. Oichi T, Oshima Y, Takeshita K, Chikuda H, Tanaka S. Evaluation of comorbidity indices for a study of patient 
outcomes following cervical decompression surgery: a retrospective cohort study. Spine. 2015;40(24):1941-1947.

17. Harse JD, Holman CDJ. Charlson's Index was a poor predictor of quality of life outcomes in a study of patients following joint replacement surgery. $J$ Clin Epidemiol. 2005;58(11):1142-1149.

18. Oba H, Takahashi J, Tsutsumimoto T, et al. Predictors of improvement in low back pain after lumbar decompression surgery: prospective study of 140 patients. J Orthop Sci. 2017;22(4):641-646.

19. Charlson ME, Pompei P, Ales KL, MacKenzie CR. A new method of classifying prognostic comorbidity in longitudinal studies: development and validation. J Chronic Dis. 1987;40(5):373-383.

20. Quan H, Li B, Couris CM, et al. Updating and validating the Charlson Comorbidity Index and score for risk adjustment in hospital discharge abstracts using data from 6 countries. Am $J$ Epidemiol. 2011;173(6):676-682.

21. Radovanovic D, Seifert B, Urban P, et al. Validity of Charlson Comorbidity Index in patients hospitalised with acute coronary syndrome. Insights from the nationwide AMIS Plus registry 2002-2012. Heart. 2014;100(4):288-294.

22. Zavascki AP, Fuchs SC. The need for reappraisal of AIDS score weight of Charlson Comorbidity Index. $J$ Clin Epidemiol. 2007;60(9):867-868.

23. Bjorgul K, Novicoff WM, Saleh KJ. Evaluating comorbidities in total hip and knee arthroplasty: available instruments. J Orthop Traumatol. 2010;11(4):203-209.

24. Zeng Z-L, Jia L, Xu W, et al. Analysis of risk factors for adjacent superior vertebral pedicle-induced facet joint violation during the minimally invasive surgery transforaminal lumbar interbody fusion: a retrospective study. Eur J Med Res. 2015;20:80. doi:10.1186/s40001-015-0174-9

25. Siemionow K, Pelton MA, Hoskins JA, Singh K. Predictive factors of hospital stay in patients undergoing minimally invasive transforaminal lumbar interbody fusion and instrumentation. Spine. 2012;37(24):2046-2054.

26. Hijji FY, Narain AS, Bohl DD, et al. Risk factors associated with failure to reach minimal clinically important difference in patient-reported outcomes following minimally invasive transforaminal lumbar interbody fusion for spondylolisthesis. Clin Spine Surg. 2018;31(1):E92-E97.

27. Khechen B, Haws BE, Bawa MS, et al. The impact of comorbidity burden on complications, length of stay, and direct hospital costs after minimally invasive transforaminal lumbar interbody fusion. Spine. 2019;44(5):363-368.

28. Ware JE. SF-36 Health Survey: Manual and Interpretation Guide. Boston, MA. Health Institute, New England Medical Center; 1993.

29. Nerland US, Jakola AS, Giannadakis C, et al. The risk of getting worse: predictors of deterioration after decompressive surgery for lumbar spinal stenosis: a multicenter observational study. World Neurosurg. 2015;84(4):1095-1102.

30. Fu K-MG, Smith JS, Polly DW Jr, et al. Correlation of higher preoperative American Society of Anesthesiology grade and increased morbidity and mortality rates in patients undergoing spine surgery. J Neurosurg Spine. 2011;14(4):470474.

31. Mobbs RJ, Phan K, Malham G, Seex K, Rao PJ. Lumbar interbody fusion: techniques, indications and comparison of interbody fusion options including PLIF, TLIF, MI-
TLIF, OLIF/ATP, LLIF and ALIF. J Spine Surg. 2015;1(1):218.

32. Wang JC, Dailey AT, Mummaneni PV, et al. Guideline update for the performance of fusion procedures for degenerative disease of the lumbar spine. Part 8: lumbar fusion for disc herniation and radiculopathy. $J$ Neurosurg Spine. 2014;21(1):48-53.

33. Steffens D, Ferreira ML, Latimer J, et al. What triggers an episode of acute low back pain? A case-crossover study. Arthritis Care Res. 2015;67(3):403-410.

34. Croft PR, Papageorgiou AC, Ferry S, Thomas E, Jayson MI, Silman AJ. Psychologic distress and low back pain. Evidence from a prospective study in the general population. Spine. 1995;20(24):2731-2737.

35. Chowdhury D, Sarkar S, Rashid MH, Rahaman A, Sarkar SK, Roy R. Influence of body mass index on low back pain. Mymensingh Med J. 2014;23(1):125-129.

36. Cassidy JD, Carroll LJ, Côté P. The Saskatchewan health and back pain survey. The prevalence of low back pain and related disability in Saskatchewan adults. Spine. 1998;23(17):1860-1866; discussion 1867.

37. Katz JN. Lumbar disc disorders and low-back pain: socioeconomic factors and consequences. J Bone Joint Surg Am. 2006;88(Suppl 2):21-24.

38. Skovron ML, Szpalski M, Nordin M, Melot C, Cukier D. Sociocultural factors and back pain. A population-based study in Belgian adults. Spine. 1994;19(2):129-137.

39. Zadro JR, Shirley D, Pinheiro MB, et al. Does educational attainment increase the risk of low back pain when genetics are considered? A population-based study of Spanish twins. Spine J. 2017;17(4):518-530.

40. Green BN, Johnson CD, Snodgrass J, Smith M, Dunn AS. Association between smoking and back pain in a crosssection of adult Americans. Cureus. 2016;8(9):e806. doi:10. 7759 /cureus. 806

41. Shiri R, Karppinen J, Leino-Arjas P, Solovieva S, Viikari-Juntura E. The association between smoking and low back pain: a meta-analysis. Am J Med. 2010;123(1):87.e7-e35.

42. Macfarlane GJ, Thomas E, Papageorgiou AC, Croft PR, Jayson MI, Silman AJ. Employment and physical work activities as predictors of future low back pain. Spine. 1997;22(10):1143-1149.

43. Nguyen TH, Randolph DC, Talmage J, Succop P, Travis R. Long-term outcomes of lumbar fusion among workers' compensation subjects: a historical cohort study. Spine. 2011;36(4):320-331.

44. Sanderson PL, Todd BD, Holt GR, Getty CJ. Compensation, work status, and disability in low back pain patients. Spine. 1995;20(5):554-556.

45. Ginsburg KB, Auffenberg GB, Qi J, et al. Risk of becoming lost to follow-up during active surveillance for prostate cancer. Eur Urol. 2018;74(6):704-707.

46. Ha K-Y, Kim S-I, Kim Y-H, Kim Y-H, Oh I-S. Predictive factors for postoperative follow-up: which patients are prone to loss to follow-up after spinal surgery? Clin Spine Surg. 2018;31(1):E25-E29.

47. Geisler FH, McAfee PC, Banco RJ, et al. Prospective, randomized, multicenter FDA IDE study of Charité artificial disc versus lumbar fusion: effect at 5-year follow-up of prior surgery and prior discectomy on clinical outcomes following lumbar arthroplasty. SAS J. 2009;3(1):17-25.

48. Blumenthal S, McAfee PC, Guyer RD, et al. A 
prospective, randomized, multicenter Food and Drug Administration investigational device exemptions study of lumbar total disc replacement with the Charité artificial disc versus lumbar fusion: part I: evaluation of clinical outcomes. Spine. 2005;30(14):1565-1575; discussion E387-E391.

49. Chung AS, Copay AG, Olmscheid N, Campbell D, Walker JB, Chutkan N. Minimum clinically important difference: current trends in the spine literature. Spine. 2017;42(14):1096-1105.

50. Sangha O, Stucki G, Liang MH, Fossel AH, Katz JN. The Self-Administered Comorbidity Questionnaire: a new method to assess comorbidity for clinical and health services research. Arthritis Rheum. 2003;49(2):156-163.

Disclosures and COI: No funds were received in support of this work. No benefits in any form have been or will be received from any commercial party related directly or indirectly to the subject of this manuscript. IRB Approval: ORA No. 14051301 .

Corresponding Author: Kern Singh, MD, Department of Orthopaedic Surgery, Rush University Medical Center, 1611 W. Harrison St, Suite \#300, Chicago, IL 60612. Phone: (312) 432-2373; Fax: (708) 409-5179; Email: kern.singh@rushortho. com.

Published 19 August 2021

This manuscript is generously published free of charge by ISASS, the International Society for the Advancement of Spine Surgery. Copyright (C) 2021 ISASS. To see more or order reprints or permissions, see http://ijssurgery.com. 